\section{Discussion}

We wish to draw attention to this disorder, because while relatively uncommon, the presentation is distinctive, and earlier recognition of our cases might have avoided some unnecessary investigation and treatment.

The commonest presentation of cutaneous mastocytosis in childhood is urticaria pigmentosa appearing as numerous small round or ovoid red or red-brown macules or papules, usually in the first six months to two years of life. ${ }^{1}$ In most cases the lesions urticate on rubbing, due to mediator release (Darier's sign), but vesiculation or frank blistering is common in lesions in infancy.

A multiplicity of these nodular or blistering lesions suggests the diagnosis but our two cases suggest that diagnosis of mastocytomas which are solitary is less easy. However, 38 cases of solitary mastocytomas in four early series ${ }^{1-4}$ indicate that the presentation is just as characteristic. Half the solitary lesions were present at birth, most by 3 months, and all but five by the age of 2 years. The usual site was on the trunk or limbs, but not palms or soles; in contrast with our cases, only two of 38 had head or neck lesions. Lesions were yellow, tan or red-brown in colour, slightly elevated or macular, and ovoid, 0.5 to $3 \mathrm{~cm}$ in largest diameter. On the basis of these appearances, the clinical differential diagnosis included melanocytic naevi, xanthomas, or juvenile xanthogranulomas. The diagnosis of solitary mastocytoma was suggested by a positive Darier's sign in only half the cases, but a history of blistering was recorded in 25 and probably more of the cases. Other cases have experienced episodic flushing. ${ }^{5}$ The diagnosis can be confirmed by biopsy; unfortunately examination of the serosanguinous blister fluid is not useful as it usually contains neutrophils rather than mast cells. The course of solitary mastocytoma is benign; those lesions not cured by excision appear to improve or resolve during early childhood. ${ }^{3}$

Blistering mastocytomas in the neonatal period or in infancy have initially been diagnosed as bullous impetigo or epidermolysis bullosa, ${ }^{1}$ or even cigarette burns (Camille Lazarro, personal communication). It is therefore important for appropriate management to recognise that in infants a history of episodic blistering or swelling at a single site is almost pathognomonic of solitary mastocytoma. ${ }^{23}$

1 Caplan RM. The natural course of urticaria pigmentosa: analysis and follow-up of 112 cases. Arch Dermatol 1963;87: 146-57.

2 Chargin L, Sachs PM. Urticaria pigmentosa appearing as a solitary nodular lesion. Arch Dermatol 1954;69:345-55.

3 Johnson WC, Helwig EB. Solitary mastocytosis (urticaria pigmentosa). Arch Dermatol 1961;84:806-15.

4 Klaus SN, Winkelmann RK. Course of urticaria pigmentosa in children. Arch Dermatol 1962;86:68-71.

5 Birt AR, Nickerson M. Generalised flushing of the skin with urticaria pigmentosa. Arch Dermatol 1959;80:311-7.

\title{
Pituitary gigantism
}

\author{
P W Lu, M Silink, I Johnston, C T Cowell, M Jimenez
}

\begin{abstract}
A case of pituitary gigantism resulting from a pituitary adenoma which secreted growth hormone is described. The patient was successfully treated by surgery, which led to the normalisation of endogenous growth hormone secretion. An acceptable final height was achieved with high dose intramuscular testosterone treatment.
\end{abstract}

The management of pituitary gigantism is difficult and often requires multiple approaches including surgery, radiotherapy, and medical treatment. It has not been established whether surgery alone can normalise spontaneous growth hormone secretion, for there is the possiblity of an underlying abnormality in the secretion of growth hormone releasing hormone and somatostatin. We report our successful experience in the transsphenoidal removal of a pituitary adenoma and the restoration of normal growth hormone secretion in a boy with gigantism.

\section{Case history}

A 13 year old boy presented with a five year history of rapid growth. He was born at full term with a weight of $3200 \mathrm{~g}$ and length of $51 \mathrm{~cm}$. He grew at a normal rate until 7 years of age when it was noticed he had large hands and required increasing shoe sizes. At the age of 10 years he was taller than a brother 14 months his senior. Immediately before referral he grew $20 \mathrm{~cm}$ over a 10 month period. There was no family history of tall stature (mother's height $163 \mathrm{~cm}$, father's height $178 \mathrm{~cm}$ ) and his four siblings were of average height.

On examination his height was $187.5 \mathrm{~cm}$ (height SD score +3.57 ) and his weight was $78 \mathrm{~kg}$. He was in Tanner stage 4 puberty (testes $12 \mathrm{ml}$ ). His hands and feet were large with slight sweating. Mild prognathism was noticed. His bone age corresponded to a male standard of 13 years according to the Greulich-Pyle standard. ${ }^{1}$ His predicted final height, calculated according to the method of Bailey-Pinneau, ${ }^{1}$ was $214 \mathrm{~cm}$.

A cranial computed tomogram demonstrated a pituitary fossa of normal size containing an intrasellar pituitary mass of $12 \mathrm{~mm}$ diameter (fig 1).

ENDOCRINE INVESTIGATIONS

Spontaneous nocturnal growth hormone secretion was assessed by taking blood samples at 20
Accepted 18 March 1992

(Arch Dis Child 1992;67:1039-41) 
minute intervals ( $8 \mathrm{pm}$ to $8 \mathrm{am}$ ) using previously described methods. ${ }^{2}$ There was persistent raised growth hormone concentration throughout the 12 hour sampling period with a mean $24.9 \mu \mathrm{g} / \mathrm{l}$. Growth hormone concentration did not return

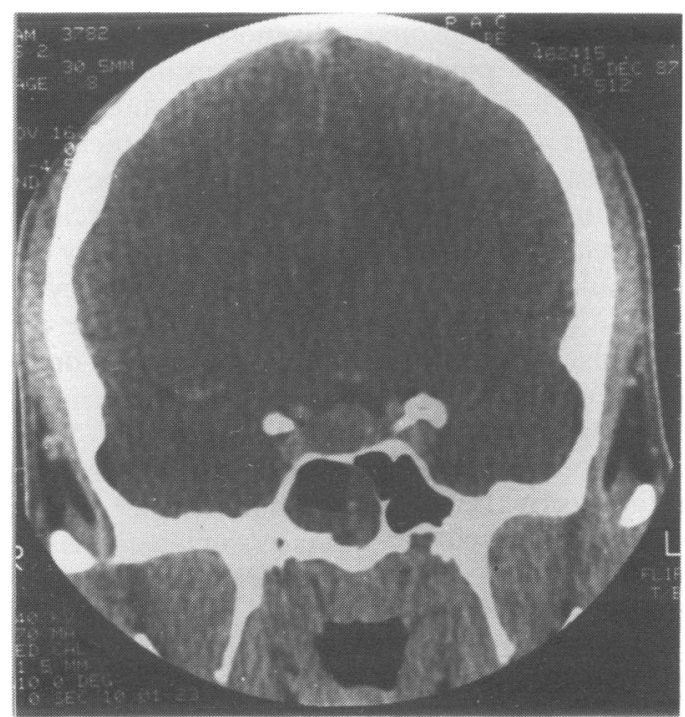

Figure 1 A computed tomogram performed beforesurgery showing a mass in the pituitary fossa which measured $12 \mathrm{~mm}$ indiameter.

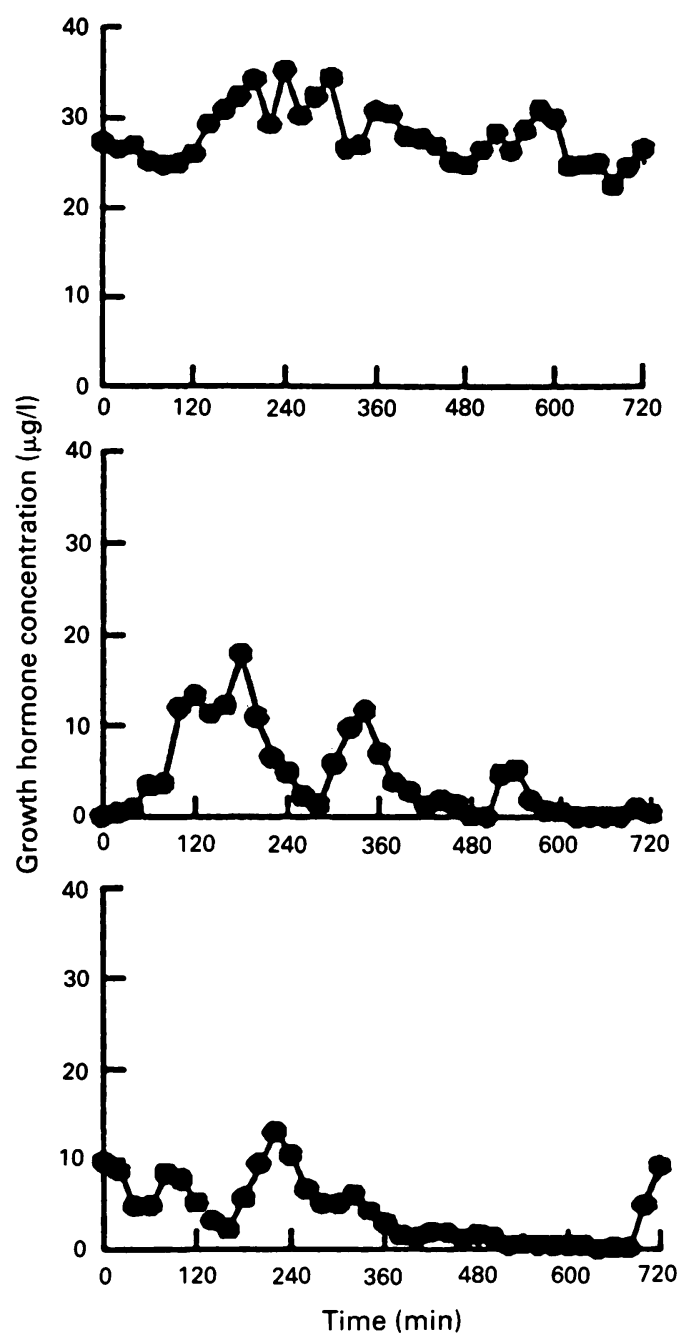

Figure 2 Nocturnal growth hormone secretory profiles assessed before surgery (upperpanel), one monih (middle panel), and 15 months (lower panel) after surgery. to the baseline and no obvious episodic secretory pattern was documented (fig 2 shows that the number of pulses defined by PULSAR algorithm $^{2}$ was three). Insulin-like growth factor I (IGF-I) was significantly increased at $134 \mathrm{nmol} / 1$ (normal range 34-97 $\mathrm{nmol} / \mathrm{l}$ ). A four hour glucose tolerance test revealed normal carbohydrate tolerance but there was no suppression of growth hormone concentrations (growth hormone concentration ranged from 35-60 $\mu \mathrm{g} / \mathrm{l})$. No other hormonal abnormality of the anterior pituitary gland was observed.

TRANSSPHENOIDAL ADENOMECTOMY

At surgery, a well defined mass in the pituitary fossa was removed by the transsphenoidal approach. No other pituitary tissue was disrupted. Histology revealed an eosinophilic adenoma.

POSTOPERATIVE PROGRESS

The patient recovered well from the operation without apparent endocrine disturbance. A 12 hour nocturnal growth hormone study was performed two months after the adenomectomy. The mean growth hormone had decreased to $4 \cdot 4$ $\mu \mathrm{g} / \mathrm{l}$ and there was a normal growth hormone secretory pattern with interpulse values below the detectable limit (fig 2). IGF-I returned to normal $(60.0 \mathrm{nmol} / \mathrm{l})$. Further assessment of

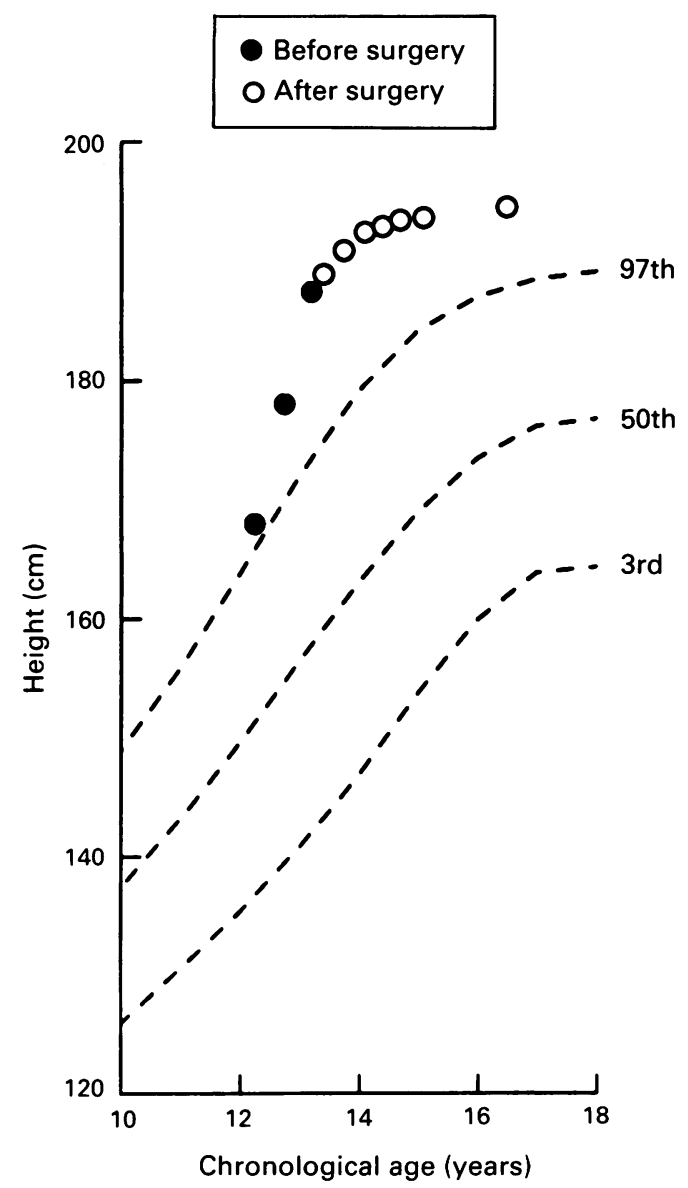

Figure 3 The height measurements obtained before and after surgery were plotted on a male growth chart with the $3 r d, 50 t h$, and 97 th centiles shown. 
spontaneous growth hormone secretion was performed 15 months after the adenomectomy. The mean growth hormone was $4.2 \mu \mathrm{g} / \mathrm{l}$ and again showed a normal growth hormone secretory pattern (fig 2). Five growth hormone pulses were defined by PULSAR algorithm on both occasions. IGF-I remained normal $(65 \cdot 8$ $\mathrm{nmol} / \mathrm{l})$. Three years after adenomectomy, the IGF-I value $(40 \cdot 2 \mathrm{nmol} / \mathrm{l})$ still remained normal.

\section{GROWTH}

In view of an estimated mature height of 214 $\mathrm{cm}$, intramuscular injections of testosterone enanthate $(500 \mathrm{mg})$ were given every two weeks starting three months after surgery. This treatment was continued for 10 months and was then stopped on the basis of relatively mature bone age (16.5 years by the Greulich-Pyle standard), giving an improved estimated mature height of $195.5 \mathrm{~cm}$. He has been followed up at yearly intervals. The most recent clinic visit was three years after surgery when he was 16.5 years of age. His height was $194.6 \mathrm{~cm}$ (height SD score $2.9)$ and he had grown only $1.2 \mathrm{~cm}$ in the preceding 15 months (fig 3). Magnetic resonance imaging scans, performed at yearly intervals, have shown no recurrence of the adenoma. He is not receiving any hormonal supplement.

\section{Discussion}

Excessive growth hormone secretion causes rapid growth and gigantism in childhood. The endogenous growth hormone secretion of our patient before surgery was characterised by increase in growth hormone throughout the sampling period with no interpulse return to baseline, nor any clearly defined pulses. This is similar to reports of a gigantic patient by Hindmarsh et al. ${ }^{3}$

A pituitary adenoma which secretes growth hormone is a rare cause of tall stature and the literature available is limited. Ritzen et al reported a case of pituitary gigantism whose growth hormone production, assessed by pharmacological stimulation tests, remained abnormal after transsphenoidal surgery and the patient subsequently required bromocriptine. ${ }^{4}$ By measuring endogenous growth hormone at two hour intervals over a period of 14 hours, Arafah et al documented one out of three patients with pituitary gigantism and 11 out of 25 had normalisation of growth hormone secretion after transsphenoidal surgery alone. ${ }^{5}$ It is considered that patients with growth hormone secreting tumours usually require additional treatment such as radiation and bromocriptine after surgery. Our patient clearly demonstrated normal pulsatile growth hormone secretion, assessed by frequent blood sampling at 20 minute intervals on two occasions after surgery. In addition, his IGF-I values have been normal during the three years of follow up. This suggests that the hypothalamus in this case was not involved in the pathogenesis of the pituitary adenoma. This differs from a previous report in which a marked increase in the frequency of growth hormone secretory pulses was observed in acromegalic patients. ${ }^{6}$

In conclusion, this is the first report of a patient with pituitary gigantism in whom successful removal of a pituitary adenoma has been documented both clinically and biochemically with normalisation of IGF-I and endogenous growth hormone secretion, assessed by frequent samples. No adverse consequences of the surgical procedure were seen in this case. Furthermore, management of tall stature by the use of testosterone therapy was also successful, the patient's final height being $20 \mathrm{~cm}$ less than the initial height prediction before surgery.

1 Greulich WW, Pyle SI. Radiographic atlas of skeletal development of the hand and the wrist. 2nd $\mathrm{Ed}$. Stanford: Stanford ment of the hand and the
University Press, 1959.

2 Lu PW, Cowell CT, Jimene\% M, Simpson JM, Silink M. Effect of obesity on endogenous growth hormone secretion in Turner's syndrome. Arch Dis Child 1991;66:1184-90.

3 Hindmarsh PC, Pringle PJ, Brook CGD. The 24-hour growth hormone secretion in a boy with gigantism. Acta Endocrinol (Copenh) 1988;117:403-8

4 Ritzen EM, Wettrell G, Davies G, Grant DB. Management of pituitary gigantism. Acta Paediatr Scand 1985;74:807-14.

5 Arafah BU, Brodkey JS, Kaufman B, et al. Transsphenoida microsurgery in the treatment of acromegaly and gigantism. F Clin Endocrinol Metab 1980;50:578-85.

6 Barkan AL. Stred SE Reno K et al. Increased growth hormone pulse frequency in acromegaly. $\mathcal{F}$ Clin Endocrinol Metab 1989;69:1225-33. 